\title{
The 12th International Symposium on Applied Rheology (ISAR)
}

Date: May 17, 2012

Venue: Grand Auditorium, Engineer House, Seoul National University, Seoul, Korea

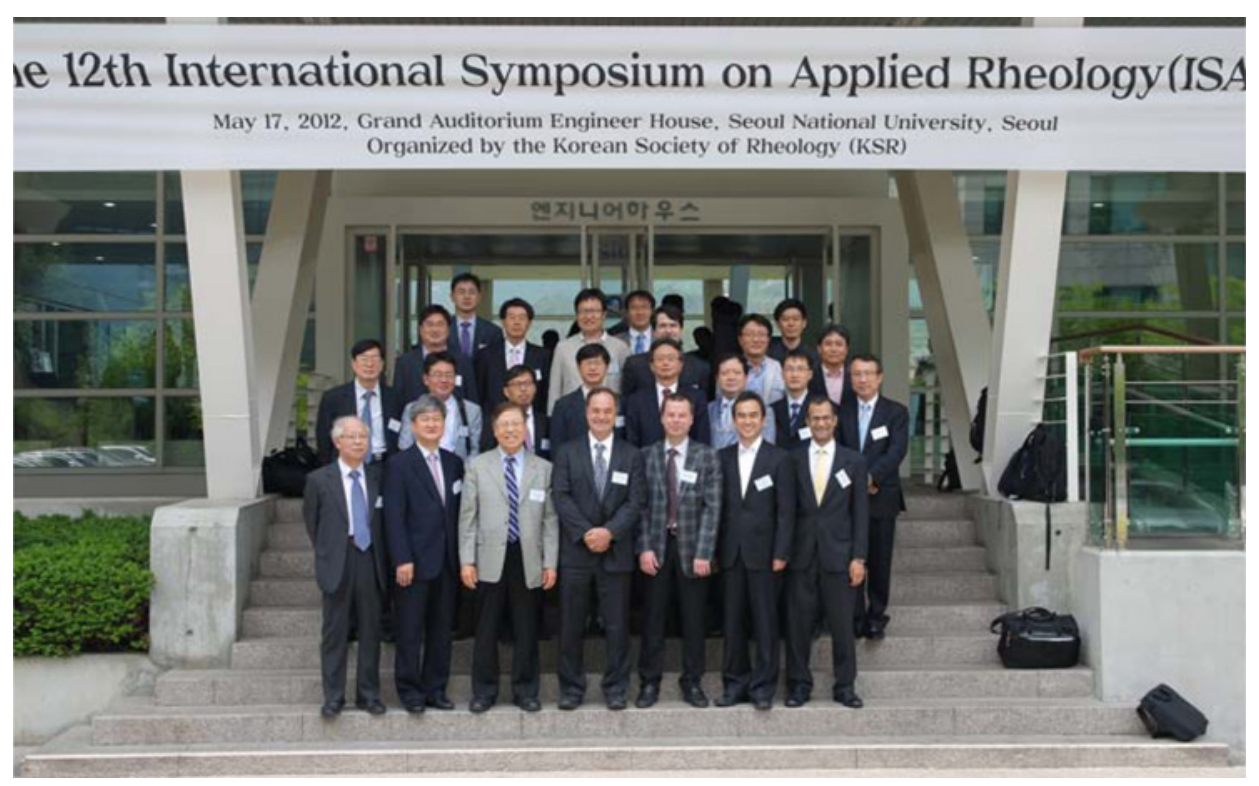

The 12th International Symposium on Applied Rheology (ISAR-12) organized by the Korean Society of Rheology (KSR) was held successfully at the Engineer House, Seoul National University on May 17, 2012. At this symposium seven invited papers were presented covering such broad areas of applied rheology as interfacial rheology, melt rheology, nano/micro-fluidic rheology, electrorheology, suspension rheology, microfluidics, computational rheology, multi-scale molecular dynamics, and so on. The invited speakers include three world-renowned scholars (Profs. Gerald G. Fuller at Stanford U., Satish Kumar at U. of Minnesota, and Seppo Syrjälä at Tampere U. of Tech., Finland) and four Korean invited scholars (Prof. Hyoung Jin Choi at Inha U., Dr. MyungSuk Chun at Korea Institute of Science and Technology, Profs. Wook Ryol Hwang at Gyeonsang Nat'l U., and Won Bo Lee at Sogang U.). Over 100 attendees from academia, research institutes, and industries greatly enjoyed the world-class presentations and ensuing discussions. The international research collaboration between the KSR and the overseas laboratories was also discussed during the symposium banquet. The presentations given at ISAR-12 are shown below.

\begin{tabular}{|l|l|}
\hline Gerald G. Fuller (Stanford U., USA) & Interfacial Rheology of Biological Interfaces \\
\hline Hyoung Jin Choi (Inha U., Korea) & Field-responsive Smart Composite Particle Suspension: Materials and Rheology \\
\hline Won Bo Lee (Sogang U., Korea) & Inhomogeneous Polymers with Reversible Bonding \\
\hline Satish Kumar (U. of Minnesota, USA) & Liquid Transfer in Printing Processes \\
\hline Myung-Suk Chun (KIST, Korea) & $\begin{array}{l}\text { Single Chain Dynamics of Biological Polyelectrolyte in Solvents by Coarse-Grained Simulations } \\
\text { and Microscope Imaging }\end{array}$ \\
\hline Seppo Syrjälä (Tampere U. of Tech., Finland) & Issues in Capillary Rheometry of Polymer Melts \\
\hline Wook Ryol Hwang (Gyeonsang Nat'l U., Korea) & Flows of Complex Fluids in Porous Media and Applications to Advanced Composites Manufacturing \\
\hline
\end{tabular}

*Corresponding author: kswong@pusan.ac.kr 